\author{
Aleksandra Dulewska \\ Akademia Wychowania Fizycznego im. Bronisława Czecha w Krakowie \\ oladulewska@wp.pl
}

\title{
Wykorzystanie nowoczesnych technologii dla celów promocyjnych przez touroperatorów prowadzących działalność na rynku polskim
}

\section{Streszczenie}

W niniejszym rozdziale dokonano rozpoznania sposobów wykorzystania nowoczesnych technologii dla celów promocji przez największych touroperatorów funkcjonujących na rynku krajowym (polskim). Badania empiryczne zrealizowano w drodze analizy środowiska internetowego, tj. stron internetowych 22 największych touroperatorów działających na rynku krajowym (polskim) oraz ich profili w mediach społecznościowych. Badania pokazały podobieństwa i różnice występujące w promocji większych touroperatorów, stopień wykorzystania poszczególnych narzędzi oraz możliwości ich zastosowania w kampaniach promocyjnych. Wyodrębniono zbiór nowoczesnych technologii, jakie stanowią podstawę funkcjonowania przedsiębiorstwa w środowisku internetowym.

\section{Wprowadzenie}

W ciągu ostatnich lat zaobserwowano coraz większą cyfryzację świata spowodowaną dynamicznym rozwojem nowoczesnych technologii. Korzysta z nich nie tylko znaczna część społeczeństwa dla celów prywatnych, ale także producenci oraz dostawcy wielu dóbr i usług funkcjonujący na rynkach krajowych i międzynarodowych. Wspomniane rozwiązania na ogół są proste w obsłudze, intuicyjne i nie generują wysokich kosztów użytkowania. W zdecydowanej większości nie wymagają nabywania specjalistycznego sprzętu - konieczne jest jedynie posiadanie np. komputera lub smartfona, aby za pomocą wbudowanego oprogramowania oraz Internetu można było z nich korzystać. 
Celem pracy jest rozpoznanie oraz analiza sposobów wykorzystania nowoczesnych technologii przez przedsiębiorstwa funkcjonujące na rynku turystycznym jako touroperatorzy. Dzięki przeprowadzonym badaniom możliwe będzie wskazanie podobieństw i różnic występujących $\mathrm{w}$ kampaniach promocyjnych większych organizatorów turystyki. W rozdziale wyodrębniono podstawowy „zbiór” nowoczesnych technologii, które dla współczesnych touroperatorów stanowią fundament kampanii promocyjnej.

Opracowanie składa się z czterech części poprzedzonych wprowadzeniem. $\mathrm{W}$ pierwszej zaprezentowano wyniki dotychczasowych badań związanych z promocją $\mathrm{w}$ środowisku internetowym. W drugiej przedstawiono zastosowane metody badań. Trzecia zawiera wyniki badań empirycznych, wyodrębniono w niej podrozdziały odpowiadające poszczególnym etapom analizy środowiska internetowego, a także podsumowanie wyników. W ostatniej części pracy zamieszczono wnioski będące rezultatem badań.

\section{Przegląd literatury}

W dzisiejszych czasach znaczna część społeczeństwa codziennie korzysta z Internetu, dlatego funkcjonowanie w środowisku wirtualnym w dobie XXI w. wydaje się czymś naturalnym. Badania stron internetowych oraz wykorzystania mediów społecznościowych mają w Polsce długoletnią tradycję. Już na początku XXI w. można było zaobserwować początek handlu elektronicznego w branży turystycznej. Za pomocą wirtualnych sklepów kupowano imprezy turystyczne czy wynajmowano sprzęt turystyczny. Niektórzy przedsiębiorcy prowadzili działalność wyłącznie $\mathrm{w}$ środowisku internetowym, a inni również stacjonarnie. Niewielka część organizatorów turystyki umożliwiała wówczas dokonanie wszelkich formalności związanych z zakupem usług za pośrednictwem swojej strony, w większości przypadków można było jedynie rezerwować imprezę turystyczną, natomiast płatności dokonywano przelewem na poczcie lub podczas osobistej wizyty w punkcie sprzedaży organizatora. Strony WWW touroperatorów zawierały m.in. takie elementy, jak: oferty imprez turystycznych, informacje prawne, medyczne i ubezpieczeniowe związane $z$ wyjazdami, przewodniki turystyczne, zdjęcia, informacje o działalności firmy, dane kontaktowe, kursy walut, newsletter. W 2002 r. przeprowadzono badania stron internetowych 30 najbardziej popularnych biur podróży funkcjonujących na polskim rynku, analizowano dostępność, wygląd oraz funkcjonalność witryn przedsiębiorców. Badania pokazały, że większość touroperatorów korzystała ze stacjonarnych form promocji i dystrybucji, stosunkowo niewielka część badanych (1/3 próby) nie miała własnych zdjęć na stronach WWW, 60\% organizatorów nie wykorzystywało animowanych form reklamy. Wygląd witryn został oceniony pozytywnie, podobnie jak intuicyjność $\mathrm{w}$ obsłudze oraz kwestie techniczne odpowiadające za funkcjonowanie strony. Podkreślono także zbyt wąski zakres usług w środowisku internetowym, który należałoby uzupełnić, wychodząc naprzeciw oczekiwaniom potencjalnych klientów (Chmielarz, 2002). 
Podobne badania serwisów internetowych pod kątem funkcjonalności witryn oraz elementów wpływających na lepsze postrzeganie firmy i wzrost sprzedaży usług zostały przeprowadzone w 2006 r. wśród 20 największych biur podróży działających na rynku turystycznym w Polsce. Podczas analizy stron WWW zwracano uwagę na elementy, które wpływają na odbiór przez potencjalnych klientów, czyli system nawigacyjny, zawartość i wygląd strony oraz jej interaktywność. Ponad połowa badanych zamieszczała na stronach WWW dane kontaktowe (90\%), informacje o firmie (90\%), adresy swoich agentów (80\%), system wyszukiwania ofert $(75 \%)$ oraz przewodniki turystyczne (70\%). Wśród najmniej popularnych elementów witryn zauważono informacje związane z reklamacjami (5\%), dostępność wirtualnego konsultanta (5\%) czy komentarze klientów (10\%). W toku badań zaobserwowano postęp (w porównaniu do wcześniejszych analiz) - przedsiębiorcy zaczęli zauważać możliwości dystrybucji usług za pośrednictwem Internetu, jednak zaledwie wśród $55 \%$ badanych strony internetowe pozwalały na dokonanie bezpośredniej rezerwacji imprezy turystycznej, nadal bez możliwości dokonania płatności online (Rusiecki, 2006).

Kolejne badania związane $\mathrm{z}$ marketingiem internetowym biur podróży działających w Polsce miały miejsce w latach 2014-2015, obejmowały znacznie większą grupę badawczą niż poprzednie - 290 podmiotów, z czego 49,31\% stanowili touroperatorzy. W głównej mierze analizowano, w jaki sposób przedsiębiorcy uzyskują dane o potencjalnych klientach - większość (co 3 badany) wskazywała stronę internetową jako istotne źródło danych, zarówno jeśli chodzi o częstotliwość odwiedzin witryny, jak i liczbę logowań - na co zwracał uwagę co czwarty podmiot. Aktywność potencjalnych klientów w mediach społecznościowych również pozwalała na pozyskanie pewnych informacji o ich preferencjach czy zainteresowaniach, jednak było to zdecydowanie rzadziej wykorzystywane źródło w porównaniu do witryn touroperatorów. Podobny problem dostrzeżono w przypadku aplikacji mobilnych, zatem przedsiębiorcy wciąż nie wykorzystują możliwości promocji, jakie dają social media oraz rozwiązania dedykowane urządzeniom mobilnym, dopiero zyskują one na popularności (Rapacz, Michalska-Dudek, 2017).

Nowoczesne technologie należą do grupy bardzo dynamicznie rozwijających się narzędzi. Postęp technologiczny wymusza automatyzację pewnych rozwiązań, których celem jest ułatwienie wykonywania wielu czynności, a dodatkowo wprowadzenie funkcji oddziałujących na większą liczbę zmysłów ludzkich. Te innowacyjne rozwiązania coraz bardziej wypierają tradycyjne formy promocji, są przyszłościowym kanałem komunikacji przedsiębiorstwa z rynkiem, który zaczyna odgrywać coraz istotniejszą rolę w wirtualnym świecie.

\section{Metodyka badań}

Celem badań było rozpoznanie, jakie nowoczesne technologie są wykorzystywane w promocji przez największych touroperatorów. Podczas badań została podjęta próba wyjaśnienia następujących kwestii: 
- Jakie nowoczesne technologie są wykorzystywane w promocji wśród wybranych touroperatorów?

- Czy wybrani touroperatorzy stosują takie same czy inne narzędzia promocji spośród nowoczesnych technologii?

W badaniach zastosowano 2 metody: analizę stron WWW oraz profili w mediach społecznościowych grupy 22 touroperatorów: Itaka, TUI Poland, Rainbow, Grecos Holiday, Wezyr Holidays, Exim Tours, Grupa Almatur, Logos Tour, Ecco Holiday, Prima Holiday, Funclub, Best Reisen Group, Wygoda Travel, Interhome, Patron Travel, Almatur Katowice, CT Poland, Student Travel, Trade\&Travel, Logos Travel, Sun\&Fun, BUT. Próba badawcza została wybrana w sposób celowy, na podstawie ratingu liderów turystyki wyjazdowej, którzy w latach 2017-2018 utrzymywali przychody na poziomie powyżej $10 \mathrm{mln}$ zł w skali roku (Frydrykiewicz, 2019). Po analizie stron WWW organizatorów turystyki badano ich działalność w mediach społecznościowych (Facebook, Instagram). Podczas przeglądu profili zwracano uwagę przede wszystkim na to, jakie rozwiązania spośród nowoczesnych technologii można dostrzec.

\section{Wyniki badań}

\section{Analiza środowiska internetowego}

Na podstawie analizy firmowych stron WWW badanych udało się pozyskać dane dotyczące stosowanych narzędzi promocji spośród nowoczesnych technologii, co zaprezentowano na rycinie 1 .

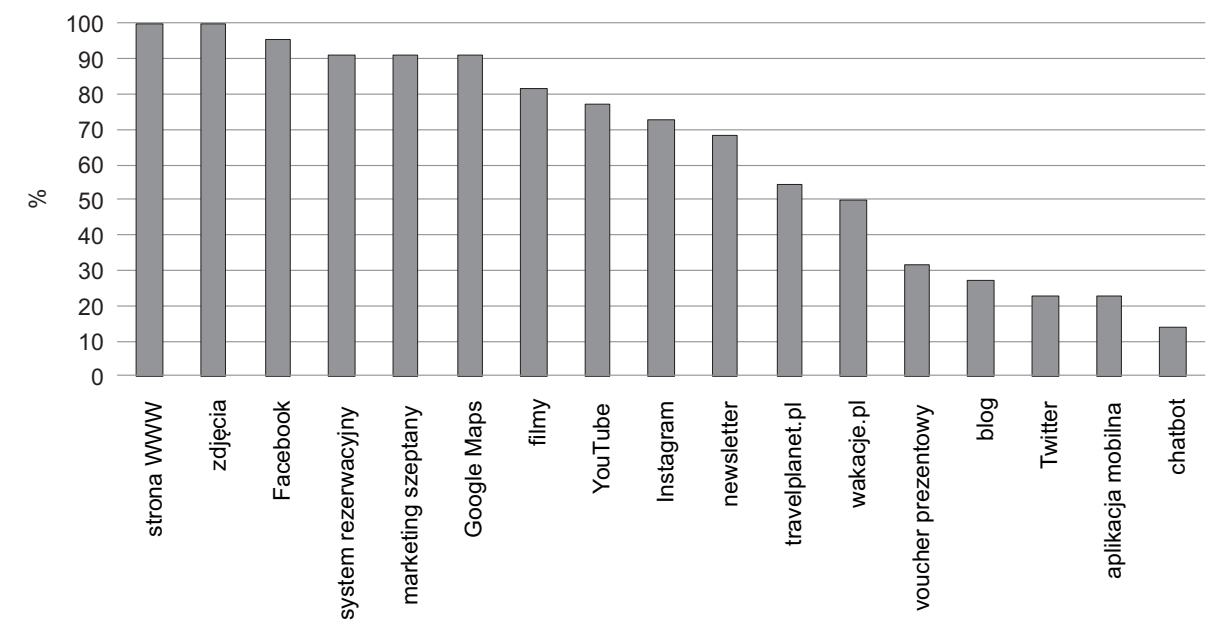

Ryc. 1. Wykorzystywanie nowoczesnych technologii wśród badanych touroperatorów Źródło: opracowanie własne.

Badania pozwoliły stwierdzić, że touroperatorzy prowadzący kampanię promocyjną $\mathrm{w}$ Internecie $\mathrm{w}$ większości stosują następujące narzędzia: stronę WWW 
(100\%), zdjęcia (100\%), profil na Facebooku (95\%), system rezerwacyjny (91\%), marketing szeptany (91\%), Google Maps (91\%) oraz filmy (82\%). Dzięki takim rozwiązaniom touroperatorzy mają możliwość zaistnienia w środowisku online, porozumiewania się z docelowymi segmentami, prezentowania ofert czy też wpływania na decyzje dotyczące wyboru punktu sprzedaży zlokalizowanego najbliżej osoby poszukującej. Stosunkowo niewielka liczba touroperatorów decyduje się na takie rozwiązania, jak: prowadzenie bloga $(28 \%)$, profil na Twitterze $(23 \%)$, aplikacja mobilna (23\%) czy chatbot (14\%). Biorąc pod uwagę aktualne trendy, aplikacje mobilne dopiero zyskują popularność, natomiast stosunkowo niski odsetek wykorzystywania pozostałych trzech narzędzi może oznaczać, że nie są one zbyt skuteczne lub są zastępowane innymi rozwiązaniami. Stosowanie chatbota, który pozwala być $\mathrm{w}$ kontakcie $\mathrm{z}$ klientem głównie poza godzinami pracy biura, okazało się najmniej popularnym rozwiązaniem wśród badanych.

W kolejnej części analizy skupiono uwagę na zależności między poziomem przychodów poszczególnych touroperatorów a liczbą stosowanych rozwiązań $\mathrm{z}$ ryciny 1 , co przedstawiono $\mathrm{w}$ tabeli 1 .

Tabela 1. Wykorzystanie nowoczesnych technologii przez poszczególnych touroperatorów

\begin{tabular}{|c|c|c|}
\hline Touroperator & Liczba stosowanych rozwiązań & $\begin{array}{c}\text { Przychody z imprez } \\
\text { turystycznych w mln zł (2018) }\end{array}$ \\
\hline Itaka & $16(76,19 \%)$ & 2503,06 \\
\hline TUI & $14(66,67 \%)$ & 2184,58 \\
\hline Rainbow & $14(66,67 \%)$ & 1467,74 \\
\hline Grecos Holiday & $14(66,67 \%)$ & 522,78 \\
\hline Exim Tours & $14(66,67 \%)$ & 205,91 \\
\hline Logos Tour & $14(66,67 \%)$ & 70,70 \\
\hline Ecco Holiday & $14(66,67 \%)$ & 52,91 \\
\hline Prima Holiday & $13(61,9 \%)$ & 46,70 \\
\hline Sun\&Fun & $13(61,9 \%)$ & brak danych \\
\hline Funclub & $12(57,14 \%)$ & 40,55 \\
\hline Coral Travel & $12(57,14 \%)$ & 638,989 \\
\hline Best Reisen Group & $11(52,38 \%)$ & 26,53 \\
\hline Wygoda Travel & $10(47,62 \%)$ & brak danych \\
\hline Almatur & $10(47,62 \%)$ & 72,22 \\
\hline Interhome & $9(42,86 \%)$ & 18,09 \\
\hline CT Poland & $9(42,86 \%)$ & 15,93 \\
\hline Student Travel & $9(42,86 \%)$ & 14,42 \\
\hline BUT & $9(42,86 \%)$ & brak danych \\
\hline Logos Travel & $7(33,33 \%)$ & 12,98 \\
\hline Patron Travel & $6(28,57 \%)$ & 18,09 \\
\hline Almatur Katowice & $6(28,57 \%)$ & 17,18 \\
\hline Trade\&Travel & $4(19,05 \%)$ & 14,20 \\
\hline
\end{tabular}

Źródło: opracowanie własne. 
Na tej podstawie można zaobserwować, że w przypadku większości badanych touroperatorów liczba wykorzystywanych narzędzi spośród nowoczesnych technologii zależy od wysokości generowanych przychodów (wg danych z 2018 r.) - im niższy poziom przychodów osiąga dany touroperator, tym mniej rozwiązań stosuje. Jest to bardzo ciekawa zależność, ponieważ znaczna część nowoczesnych technologii to bezpłatne narzędzia, niewielki ich zbiór obejmuje płatne formy promocji.

\section{Analiza profili w mediach społecznościowych}

Badanie profili $\mathrm{w}$ mediach społecznościowych zostało przeprowadzone 11-18 maja 2020 r., a dotyczyło działalności od początku 2020 r. Na podstawie analizy aktywności poszczególnych touroperatorów stworzono kartę ukazującą standardowy profil organizatora na Facebooku, co przedstawiono w tabeli 2.

Tabela 2. Analiza profili w mediach społecznościowych - karta typowego touroperatora na Facebooku

\begin{tabular}{ll}
\hline \multicolumn{2}{c}{ Rodzaj medium społecznościowego: www.facebook.com } \\
\hline Informacje o firmie zamieszczone & - data założenia działalności [80\%] \\
na profilu (zakładka & - dane kontaktowe: telefon [100\%], adres \\
„Informacje”) & strony WWW [95\%], link do czatu w aplikacji \\
& Messenger [85\%], e-mail [75\%] \\
& - krótki opis działalności [95\%] \\
& - informacje o oferowanych produktach [70\%] \\
& - strona główna [100\%] \\
Zakładki widoczne na profilu & zdjęcia [100\%] \\
użytkownika & - filmy [95\%] \\
& - informacje [100\%] \\
& - posty [100\%] \\
& - społeczność [100\%] \\
& - zdjęcia nawiązujące do oferty [95\%] \\
& - krótkie informacje o destynacjach/atrakcjach \\
Treści publikowane na profilu & turystycznych [75\%] \\
(zakładka „Posty”) & informacje i linki do aktualnych ofert wycieczek \\
& - informacje o promocjach [85\%] \\
& - życzenia świąteczne [75\%] \\
& - autorskie zdjęcia [95\%] \\
Nowoczesne technologie & linki do firmowej strony WWW [80\%] \\
widoczne na koncie użytkownika &
\end{tabular}

Źródło: opracowanie własne.

Zgodnie z zaprezentowanymi danymi wśród informacji zamieszczanych o firmie znalazły się takie pozycje, jak: data rozpoczęcia działalności, dane kontaktowe, krótki opis działalności oraz informacje o oferowanych produktach. Są to dokładnie takie same dane, jakie można znaleźć na stronach WWW touroperatorów; można zatem powiedzieć, że konto na Facebooku również jest wizytówką 
firmy, dzięki której potencjalny klient może znaleźć podstawowe informacje o prowadzonej przez przedsiębiorcę działalności.

Kolejnym etapem analizy było rozpoznanie elementów z zakresu nowoczesnych technologii, jakie występują na profilach badanej grupy, co zostało zaprezentowane na rycinie 2 .

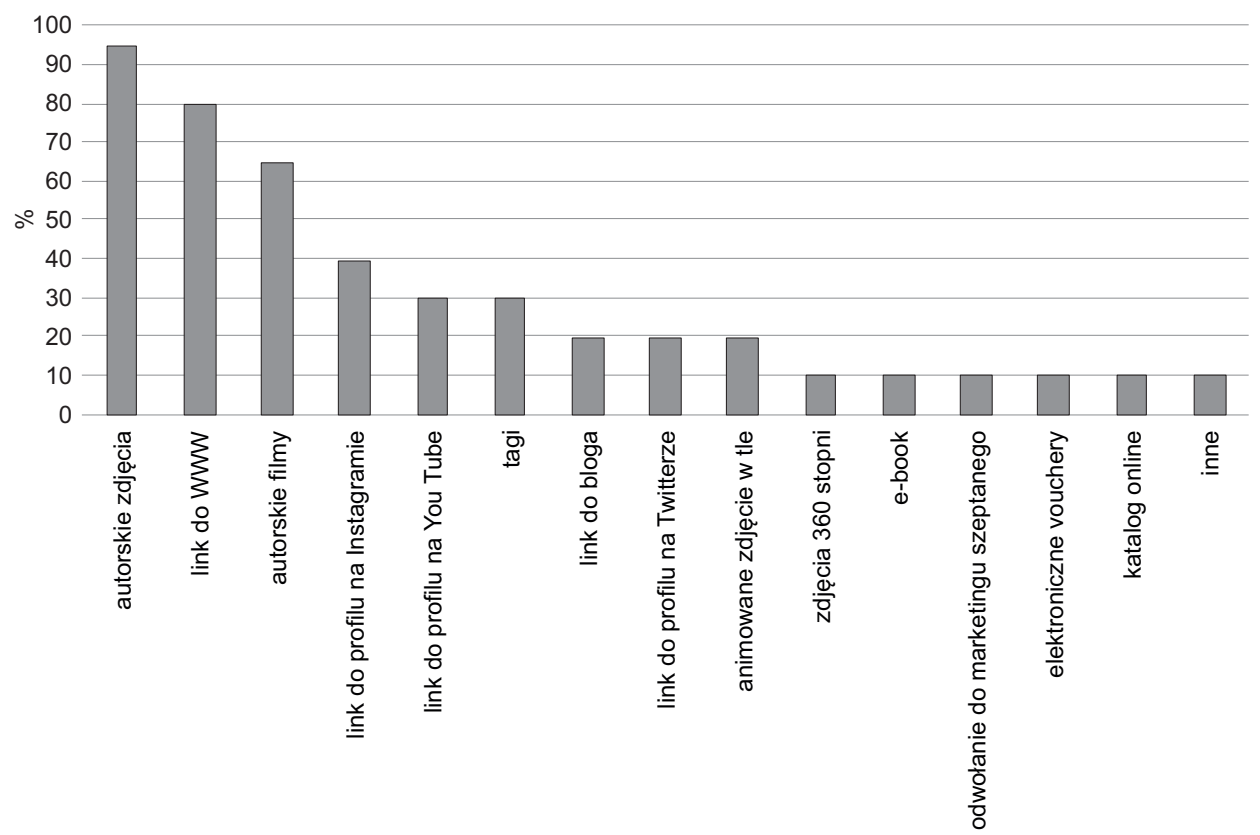

Ryc. 2. Nowoczesne technologie widoczne na profilu użytkownika na Facebooku Źródło: opracowanie własne.

Poza nowoczesnymi technologiami, jakie zostały zamieszczone na karcie typowego profilu touroperatora, większość badanej grupy publikuje również autorskie filmy (65\%). Blisko połowa przedsiębiorców (40\%) udostępnia link do swojego profilu w czasie aktywności na Facebooku. Zaskakujące jest, że zaledwie $30 \%$ touroperatorów, publikując treści, używa tagów związanych z prezentowanymi $\mathrm{w}$ poście informacjami. Powiązanie $\mathrm{z}$ wiadomościami zawartymi w różnych wpisach $z$ odwołaniem do strony WWW za pomocą tagów wpływa na lepsze pozycjonowanie witryny $\mathrm{w}$ momencie wyszukiwania różnych haseł $\mathrm{w}$ przeglądarce internetowej. Ciekawym przypadkiem zyskującym na popularności są zdjęcia $360^{\circ}$, które wykorzystuje jedynie 2 touroperatorów spośród badanej grupy: Itaka oraz Rainbow. W równie niewielkim stopniu przedsiębiorcy publikują posty z informacjami takimi, jak: e-book, odwołanie do marketingu szeptanego (który pełni przecież istotną rolę $\mathrm{w}$ procesie decyzyjnym obecnego konsumenta usług), elektroniczne vouchery oraz katalogi online. Na etapie tej analizy został dostrzeżony jeszcze jeden nietypowy format publikowanych zdjęć, mianowicie 3D. Rozwiązanie to wyróżnia jednego z touroperatorów w badanej grupie - Itakę. 
W drugiej części analizy skupiono uwagę na badaniu profili touroperatorów na Instagramie; na tej podstawie również stworzono kartę ukazującą standardowy profil organizatora (z elementami, które znalazły zastosowanie wśród co najmniej 70\% badanych), co przedstawiono w tabeli 3 .

Tabela 3. Analiza profili w mediach społecznościowych - karta typowego touroperatora na Instagramie

\begin{tabular}{ll}
\hline \multicolumn{2}{c}{ Rodzaj medium społecznościowego: www.instagram.com } \\
\hline $\begin{array}{l}\text { Informacje o firmie } \\
\text { zamieszczone na profilu }\end{array}$ & Brak \\
\hline $\begin{array}{l}\text { Czy profil jest } \\
\text { ogólnodostępny? }\end{array}$ & Tak \\
\hline $\begin{array}{l}\text { Treści publikowane na } \\
\text { profilu }\end{array}$ & $\begin{array}{l}\text { - zdjęcia destynacji i atrakcji turystycznych z oferty [86\%] } \\
\text { - pobudzanie aktywności obserwujących użytkowników - } \\
\end{array}$ \\
$\begin{array}{ll}\text { prośby o dodawanie komentarzy w nawiązaniu do tematu } \\
\text { wpisu [79\%] }\end{array}$ \\
$\begin{array}{ll}\text { Nowoczesne technologie } \\
\text { widoczne na koncie }\end{array}$ & $\begin{array}{l}\text { - autorskie zdjęcia [86\%] } \\
\text { użytkownika }\end{array}$
\end{tabular}

Źródło: opracowanie własne.

$\mathrm{Na}$ podstawie wskazanej karty można stwierdzić, że profil na Instagramie nie jest tak wykorzystywany, jak konto na Facebooku - być może ze względu na mniejsze możliwości tego medium. Znaczna część touroperatorów publikuje zdjęcia destynacji i atrakcji turystycznych $z$ oferty, pobudza aktywność odbiorców poprzez nawiązywanie konwersacji w postaci zadawania pytań odnoszących się do tematów wpisu (zwykle są to pytania o doświadczenie i przeżycia $z$ danego miejsca, którego fotografia jest opublikowana), a także informacje o promocjach. Wśród nowoczesnych technologii, jakie można zauważyć na profilach badanej grupy, są w przeważającej liczbie autorskie zdjęcia oraz tagi nawiązujące do tematu wpisu. Te ostatnie są dość charakterystycznym elementem, dlatego zaskakujące jest to, że jednak nie wszyscy touroperatorzy stosują tę technikę. Odpowiednie wykorzystanie tego narzędzia pozwala na dotarcie do znacznej grupy odbiorców, ponieważ wpis pojawia się wówczas na innych stronach na Instagramie; bardzo często firmy stosują jakieś własne tagi, dzięki którym łatwo jest im stworzyć połączenie między poszczególnymi mediami społecznościowymi a stroną WWW, pod warunkiem że wszędzie używają tego elementu.

Kolejnym $z$ aspektów analizy są nowoczesne technologie widoczne na profilach użytkowników, co zostało przedstawione na rycinie 3 . Na podstawie tej części danych można powiedzieć, że udostępnianie zdjęć oraz stosowanie tagów stanowią pewne minimum poziomu aktywności użytkowników Instagrama. W przypadku tego medium zbiór rozwiązań jest nieco uboższy: większość firm udostępnia linki do firmowej strony WWW (57\% badanych) podczas zamieszczania również innych informacji we wpisie. Niewielka liczba touroperatorów publikuje autorskie filmy (21\%), najrzadziej spotykanym elementem okazało się 
udostępnianie linków do bloga (7\% badanych). Można więc zauważyć, że aktywność użytkowników Instagrama w znacznej części opiera się na publikowaniu zdjęć wraz z odpowiednim opisaniem ich za pomocą tagów, nie przekazuje się tu informacji w postaci dłuższych wpisów, co może mieć miejsce np. na Facebooku. To medium społecznościowe opiera się głównie na elementach graficznych, a nie przekazie merytorycznym.

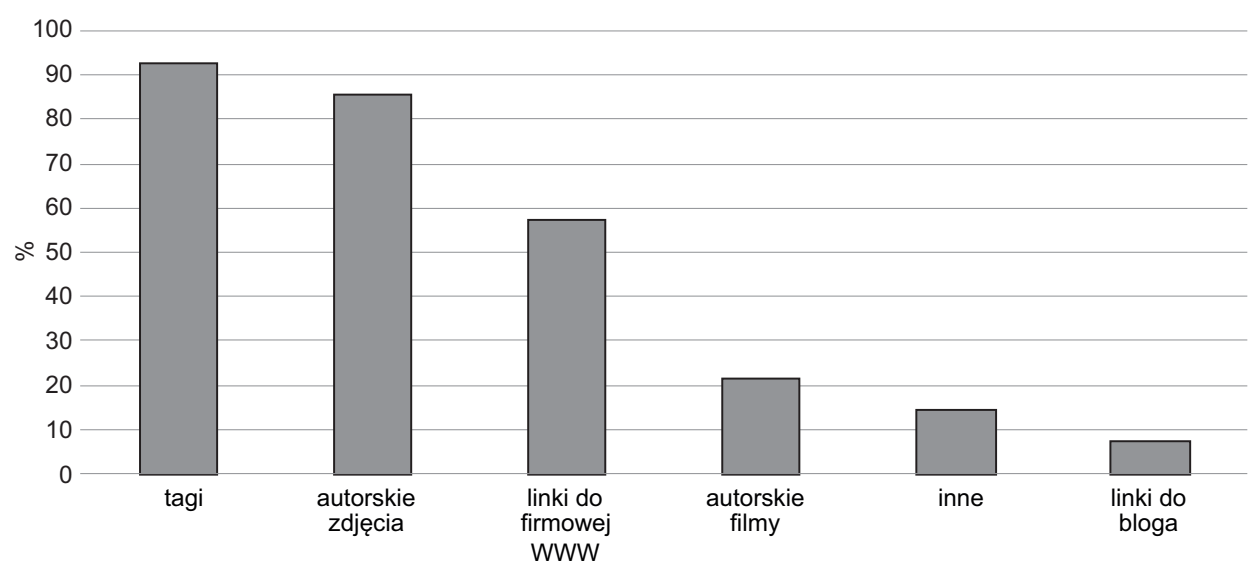

Ryc. 3. Nowoczesne technologie widoczne na profilach użytkowników na Instagramie Źródło: opracowanie własne.

Dotychczasowe rozważania pokazują, że największą ilość różnorodnych rozwiązań obserwuje się na Facebooku, który jest najbardziej dynamicznie rozwijającym się medium. Analizując karty prezentujące typowe profile touroperatorów w mediach społecznościowych, można zauważyć, że jedynie trzech przedstawicieli posiada wszystkie informacje tam zawarte: TUI, Rainbow oraz Sun\&Fun.

\section{Zakończenie}

Na podstawie danych zebranych podczas badań można wysunąć szereg wniosków dotyczących wykorzystywania nowoczesnych technologii w promocji przez największych touroperatorów na rynku polskim.

Zgromadzono szczegółowe informacje o tym, jakie nowoczesne technologie są wykorzystywane w promocji przez badanych. Najważniejszymi elementami z tego zakresu są witryna internetowa przedsiębiorstwa oraz media społecznościowe, bez których firma nie ma szans na zaistnienie w świadomości odbiorców w obecnych czasach. Najwięksi touroperatorzy stosują podobne rozwiązania $\mathrm{w}$ zakresie prowadzonych kampanii promocyjnych w środowisku internetowym.

Mając na uwadze wyniki dotychczasowych badań, warto zaznaczyć, że touroperatorzy coraz częściej sięgają po innowacyjne rozwiązania, wychodząc naprzeciw oczekiwaniom klientów, którzy spędzają więcej czasu w środowisku internetowym. Zauważają oni nowe możliwości nowoczesnych form promocji oraz 
korzyści, jakie dają, co również wpływa na konkurencyjność i przewagę firmy na rynku krajowym.

Nowoczesne technologie znacznie ułatwiają prowadzenie kampanii promocyjnych $z$ uwagi na spersonalizowany charakter, są przystępne i wygodne w użyciu dla przedsiębiorców oraz potencjalnych klientów. Mając na uwadze nieustający postęp technologiczny na świecie, można stwierdzić, że nowoczesne technologie są przyszłościowym rozwiązaniem, które prawdopodobnie wkrótce zastąpi tradycyjne narzędzia promocji dzięki powszechności ich stosowania. Bez wątpienia są skuteczniejszym rozwiązaniem stosowanym $\mathrm{w}$ promocji touroperatorów w porównaniu do tradycyjnych odpowiedników, które dodatkowo generują dużo większe koszty kampanii.

\section{Literatura}

Bonek T., Smaga M. (2012). Biznes w Internecie. Praktyczny poradnik o marketingu, sprzedaży, public relations on-line i promocji w mediach społecznościowych. Wydawnictwo Wolters Kluwer, Warszawa.

Chmielarz W. (2002). Analiza i ocena stron internetowych biur turystycznych działających na terenie Polski. Folia Oeconomica, Łódź.

Frydrykiewicz F. (2019). 29 liderów turystyki wyjazdowej - ratingi i ranking. Rzeczpospolita (http://info.rp.pl/temat/984572.html; dostęp: 16.03.2020).

Furgała A. (2015). Social Media (FB, YouTube) oraz narzędzie Web Analytics (Google Analytics) w budowaniu wizerunku. W: J. Gołuchowski, Z. Spyra (red.), Nowe media i technologie w komunikacji marketingowej - współczesne wyzwania i trendy. Wydawnictwo Proksenia, Kraków.

Kruczek Z., Walas B. (2010). Promocja i informacja w turystyce. Wydawnictwo Proksenia, Kraków.

Lipska A. (2015). Blog firmowy jako skuteczne narzędzie komunikacji marketingowej. W: J. Gołuchowski, Z. Spyra (red.), Nowe media i technologie w komunikacji marketingowej - współczesne wyzwania i trendy. Wydawnictwo Proksenia, Kraków.

Pawlicz A. (2012). E-turystyka. Wydawnictwo Naukowe PWN, Warszawa.

Rapacz A., Michalska-Dudek I. (2017). Wiedza o nabywcach usług turystycznych w świetle badań ankietowych biur podróży w Polsce. Ekonomiczne Problemy Turystyki, 38.

Rusiecki P. (2006). Analiza funkcjonalna serwisów internetowych biur podróży na rynku organizatorów imprez turystycznych w Polsce. W: T. Porębska-Miąc, H. Sroka (red.), Systemy wspomagania organizacji.

Wielki J. (2000). Elektroniczny marketing poprzez Internet. Wydawnictwo Naukowe PWN, Wrocław.

Wiktor J.W. (2001). Promocja. System komunikacji przedsiębiorstwa z rynkiem. Wydawnictwo Naukowe PWN, Warszawa.

\section{Use of modern technologies for promotional purposes by tour operators functioning on the Polish market}

The purpose of this article is recognising the ways of using modern technologies for promotional purposes by biggest touroperators functioning on domestic market (Polish). Em- 
pirical research was completed by analysis of internet environment - the internet websites of 22 biggest touroperators functioning on domestic market (Polish) and their profiles in social media. Research has shown similarities and differences occurring in promotion of bigger touroperators, the degree of use of individual tools and possibilities of their uses in promotional campaigns. A basic set of modern technologies which constitute the basis of functioning of enterprises in internet environment was determined.

Translated by Aleksandra Dulewska 